\title{
Ergenler Arasında Çakmak Gazı Soluma Sonucu Ani Ölüm: Olgu Sunumu
}

\section{Sudden Death due to Lighter Fluid Inhalation among Adolescent: A Case Report \\ Hülya Karadeniz ${ }^{1}$, Hüseyin Çetin Ketenci ${ }^{1}$, Halil Boz ${ }^{1}$, Gökhan Kazındır ${ }^{1}$, Ismail Birincioğlu ${ }^{2,3}$, Özgür Turna}

${ }^{1}$ Adli Tip Kurumu Trabzon Grup Bașkanlığı, Trabzon

${ }^{2}$ Karadeniz Teknik Üniversitesi Tip Fakültesi Adli Tip Anabilim Dalı, Trabzon

${ }^{3}$ Karadeniz Teknik Üniversitesi Adli Bilimler Enstitüsü, Trabzon

\section{Özet}

İnhalan maddeler (bazen "uçucu maddeler" olarak da adlandırılırlar) yaygin olarak bulunan, kolaylıkla temin edilebilen ve özellikle ergenler tarafından kötüye kullanılan maddelerdir. İnhalan kötüye kullanımı kültürel ve coğrafi sınırları aşan, dünya çapında bir sağlık sorunudur. Türkiye'de de bu sorunun giderek yaygınlaştığı gözlemlenmektedir. Uçucu maddeleri içeren ürünlerin ucuz olması, temininin yasal yollardan ve kolayca sağlanabilmesi (süpermarket, kırtasiye, ilaç depoları, işyerleri vs), söz konusu maddelerin çabuk etki göstermesi ve istenmeyen bulgularının hızla kaybolması gibi nedenler çocuk ve ergenlerde kullanımını kolaylaştırmaktadır.

Arkadaş grubu içerisinde bütan içerikli çakmak gazı dolum tüpünden gaz soluma sonrası ani ölüm meydana gelen on yedi yaşındaki erkek olgu, olay ortamı ve otopsi bulguları ile sunulmaktadır.

$\mathrm{Bu}$ çalışmada; çocuk ve genç erişkin yaş gruplarında sıklığ giderek artan uçucu maddelerin kötüye kullanım nedenleri ile meydana gelen ölüm olgularında adli otopsinin ölüm nedeninin saptanmasındaki yeri ve öneminin vurgulanması amaçlanmıştır.

Anahtar Kelimeler: Çakmak Gazı, Bütan, Uçucu Madde, Ergen, Adli Tıp, Otopsi.

\section{Giriș}

İnhalan maddeler (bazen "uçucu maddeler" olarak da adlandırılırlar) yaygın olarak bulunan, kolaylıkla temin edilebilen ve özellikle ergenler tarafından kötüye kullanılan maddelerdir (1). İnhalan kötüye kullanımı kültürel ve coğrafi sınırları aşan, dünya çapında bir sağlık sorunudur (2-4). Ülkemizde de, kesin rakamlar olmamakla birlikte, bu sorunun giderek yaygınlaştı̆̆ gözlemlenmektedir. Uçucu maddeleri içeren ürünlerin ucuz olması, temininin yasal yollardan ve kolayca sağlanabilmesi (süpermarket, kırtasiye, ilaç depoları, işyerleri vs), söz konusu maddelerin çabuk etki göstermesi ve istenmeyen bulgularının hızla kaybolması gibi nedenler çocuk ve ergenlerde kullanımını kolaylaştırmaktadır (5).

Arkadaş grubu eğilimleri, rol model alma, sosyoekonomikkültürel etmenler, ailevi ve bireysel problemler gibi çok çeşitli faktörler nedeniyle, bazen sadece merak ve arkadaş yönlendirmesi gibi nedenlerle çocuk, ergen ve genç erişkinler

Sorumlu Yazar: Doç.Dr. İsmail Birincioğlu

Karadeniz Teknik Universitesi Tip Fakültesi

Adli Tip Anabilim Dal, Trabzon

E-mail: ismbir@yahoo.com

Geliş: 11.01.2015 Düzeltme: 03.02.2015

Kabul: 23.02.2015

\begin{abstract}
Inhalant substances (sometimes called "volatile substances") are widely available and frequently misused, especially by adolescents. Abuse of inhalants is a world-wide problem crossing cultural and geographic borders. It has been observed that inhalant abuse becomes more prevalent in Turkey. Cheapness, easy and legal (supermarkets, drug reservoirs, stationery, commercial buildings) procurement of the products including volatile substances and rapid effect, fast disappearance of unwanted findings makes these substances easier to use in children and adolescents.
\end{abstract}

Here we present autopsy findings and death scene investigation of a sudden death case of a seventeen-year-old male due to inhalation of volatile from butane containing lighter gas tube.

In this study, it is intended to emphasize the role and significance of forensic autopsy on the determination of death cases as well as the increasing prevalence of inhalant abuse in adolescent and young adult age groups

Keywords: Lighter Fluid, Butane, Volatile Substance, Adolescent, Forensic Medicine, Autopsy.

uçucu maddeleri kötüye kullanabilirler. Uçucu madde alımı, sonrasında kısa süre içinde öfori, eksitasyon ve neşeli davranışlar gelişmesi nedeniyle “zevk verici” olarak kabul edilmektedir $(6,7)$.

Uçucu madde kullanmaya başlayan ergenler için madde kullanımı zamanla arkadaşları ile yaptığı bir aktivite halini almaktadır. Genelde toplumdan uzak parklar, köprü altları, inşaatlar, terk edilmiş boş evler, tren rayları gibi mekanlarda bu maddeyi kullanmaktadırlar (8).

Uçucu madde inhalasyonuna başlama yaşının istisnai olgular dışında 9-15 yaş aralığında olduğu ve en yaygın olarak ergenlik döneminde ve erkek cinsiyette (\%90) görüldüğü belirtilmektedir. Ülkemizde uçucu maddelerin kötüye kullanımına dair kesin veriler olmamakla beraber kullanım sıklı̆̆ının özellikle genç nüfusta 2001-2004 yılları arasında $\% 40.5$ oranında arttığ belirtilmektedir $(9,10)$.

Uçucu madde inhalasyonu önemli ölçüde morbidite ve mortaliteden sorumludur. Kullanımına bağlı olarak suffokasyon, travma, vagal inhibisyon, solunum depresyonu ve kardiyak aritmi gibi nedenlerle ani ölüm meydana gelmektedir. Ani ölümlerin \%50'den fazlasının direk toksik (özellikle 
kardiyak) etkilere bağlı olduğu belirtilmiştir $(10,11)$. Bu bağlamda meydana gelen ölümlerin sayısında sürekli bir artış gözlenmektedir. Bu olgularda, ölüm sebebinin ve orijininin tespiti, otopsi yapılmasına rağmen çoğunlukla güçlükle saptanabilmektedir (12).

Bu çalışmada; çocuk ve genç erişkin yaş gruplarında sıklığ giderek artan uçucu maddelerin kötüye kullanım nedenleri ve meydana gelen ölüm olgularında adli otopsinin ölüm nedeninin saptanmasındaki yeri ve öneminin vurgulanması amaçlanmıştır.

\section{Olgu Sunumu}

On yedi yaşında bir erkektir. Adli dosya içeriğinde mevcut arkadaşlarının beyanlarında; 27.01.2014 tarihinde boş bir evin çatısında birkaç arkadaşı ile birlikteyken marketten satın aldığ çakmak gazı tüpünden ağız yolu ile gaz soluması sonrası aralarında çıkan sözlü bir tartışma sırasında nefes alamadığını söylediği ve fenalaştığ 1 , hırıltılı sesler çıkardığı, olduğu yere düşerek kafasını zemine çarptı̆̆ı, yüzüne su atarak ayıltılmaya çalışıldığı, çă̆rılan ambulansla hastaneye kaldırıldığı, yapılan müdahalelere rağmen netice alınamayarak hastanede öldüğü ifade edilmektedir. Yine arkadaşlarının ifadesinde; ölen kişinin önceden de zaman zaman çakmak gazı dolum tüpünden içine gaz çektiği belirtilmektedir. Olgunun ailesi ise çocuklarının çakmak gazı kullandığını bilmediklerini ifade etmişlerdir. Şahsa Adli Tıp Kurumu Trabzon Grup Başkanlığı Morg İhtisas Dairesinde 28.01.2014 tarihinde sistematik otopsi yapılmış ve 18.03.2014 tarihli otopsi raporu düzenlenmiştir.

$\mathrm{Bu}$ çalışmada N-butan gazının tespiti Perkin Elmer CLARUS 500 Gaz Kromatografi ve Perkin Elmer Headspace sampler Turbo Matrix 16 cihazı ile yapıldı. Analizlerde $60 \mathrm{~m} \mathrm{x}$ $0.53 \mathrm{~mm}$ BP20 polietilenglikol kapiller kolonu ve taşı1ıı gaz olarak azot kullanıldı. FID dedektörünün sıcaklığı $250{ }^{\circ} \mathrm{C}, \mathrm{A}$ Cap $120{ }^{\circ} \mathrm{C}$, enjeksiyon bölümünün sıcaklığg $60{ }^{\circ} \mathrm{C}$, kolon sıcaklığ $140^{\circ} \mathrm{C}$ ve taşıyıcı gaz 20 psi şartlarında çalışıldı.

Olguya ait kan örneğinden, otomatik pipetle $200 \mu l$ alınarak 20 ml'lik gaz kromatografi/headspace vialine konuldu, üzerine $100 \mu$ internal standart çözeltisi (n-bütanol) insülin şırınga ile ilave edildi. Vial, metal halkalı silikon kapakla crimping yardımıyla bekletilmeden kapatıldı. Vorteksle karıştırılarak analiz edildi.

Piyasadan temin edilen bütan gaz içerikli çakmak gaz dolum tüpü analizde referans olarak kullanıldı.

Otopsi raporunda; 17 yaşında, $167 \mathrm{~cm}$ boy ve $50-55 \mathrm{~kg}$. ağırlığında erkek cesedinde dış muayenede resusitasyon işlemine bağlı olduğu düşünülen göğüs ön solda ekimotik dermal bulgular ile damar yolu giriş lezyonlarına bağlı iğne pikür izleri dışında patolojik veya travmatik herhangi bir bulgu saptanmadı̆̆ı,
İç muayenede, beyin ve beyincik ağırlığında hafif derecede artış (1680 gr.), gyruslarda kısmi düzleşme, her iki akciğerin ağırlıklarında ileri derecede artma (sağ 1050 gr., sol 925 gr.), yer yer kümeleşen subplevral yaygın kanama ve yoğun ödem, trakea lümeninde sıvalı halde köpük içerik, kalbin yüzeyinde noktasal kanamalar tespit edildiği (Resim 1,2). Histopatolojik incelemede ise; akciğerlerde intraalveolar taze kanama ve yaygın atelektazi, karaciğerde şiddetli portal inflamasyon saptandığ 1 kayıtlıdır. Adli Tıp Kurumu Trabzon Grup Başkanlığı Kimya İhtisas Dairesinde "Headspace-Gaz Kromatografisi (HS/GC)” yöntemiyle femoral kanda yapilan analiz sonucunda n-butan varlı̆̆ 1 kalitatif olarak tespit edildi. Analizde referans olarak kullanılan piyasadan temin edilen bütan gaz içerikli çakmak gaz dolum tüpünden elde edilen verilerle uyumlu olduğu görüldü (Şekil 1-2)

“Co-Oximeter" cihazı ile yapılan ölçümlerde ise karboksihemoglobin oranı \% 2.1 olarak bulundu.

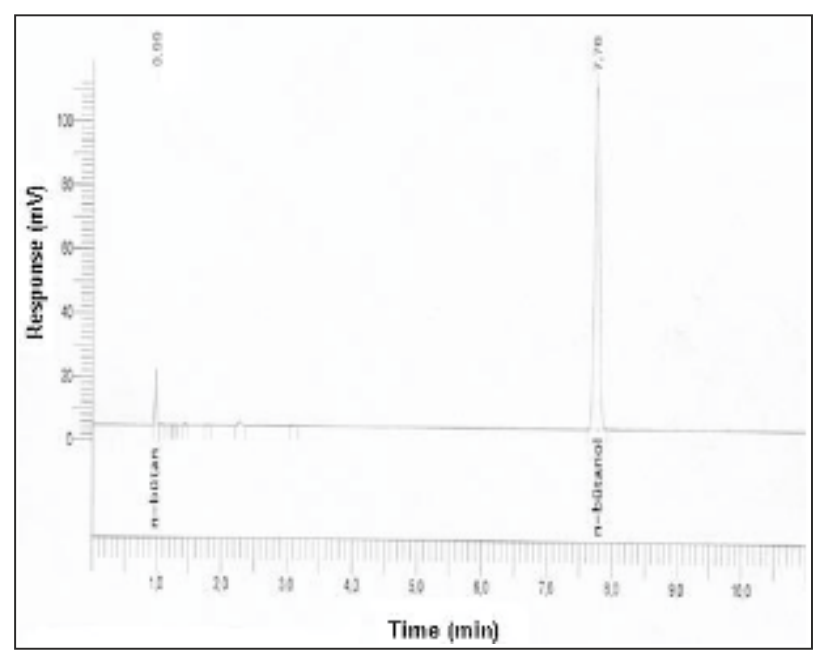

Şekil 1. Olguda kan numunesinden elde edilen grafik.

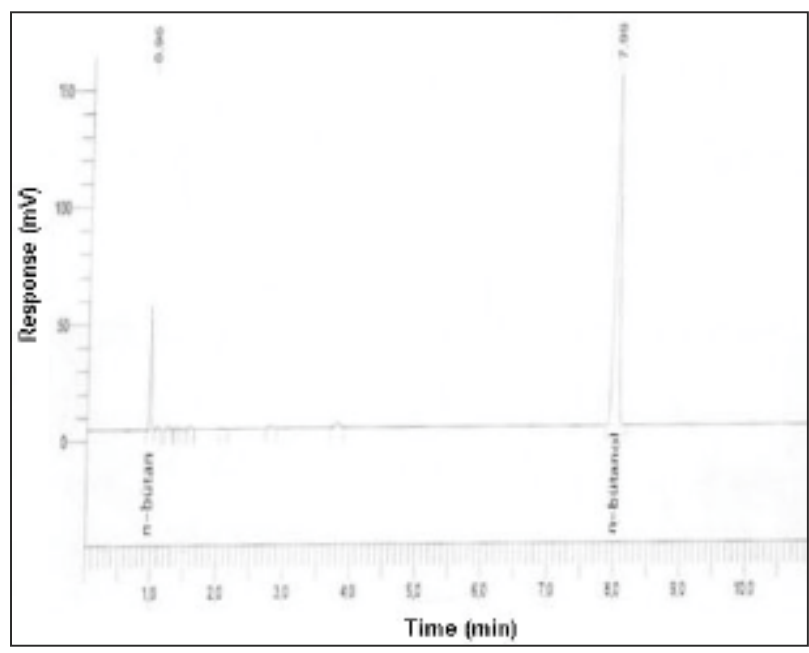

Şekil 2. Çakmak gazından elde edilen grafik. 


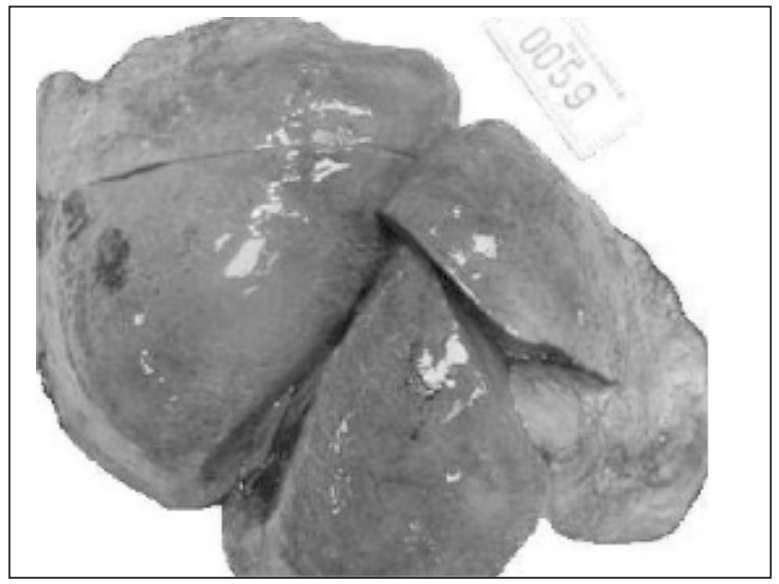

Resim 1. Akciğerde subplevral yaygın noktasal ve yer yer kümeleşen kanamalar (Tardieu Lekeleri).

\section{Tartışma ve Sonuç}

Literatürde uçucu madde kullanımının en çok erkek cinsiyeti ve ergenlerde olduğu konusunda fikir birliği mevcuttur (13-15). Olgumuz da erkek olup on yedi yaşındadır. Literatürlerdeki yaş ve cinsiyet grubuyla olgumuzun uyuştuğu görülmektedir. Bu maddelerin kullanımı ile ilgili çeşitli risk grupları belirlenmiştir: aile içi sorun yaşayan çocuk ve ergen olmak $(16,17)$, alt sosyoekonomik sınıf (18), sokak çocukları (19), işyerlerinde uçucu madde kullanan meslek grupları (ayakkabı tamircisi, matbaa vb.) daha pahalı maddeleri alamayan madde bağımlıları $(20,21)$ riskli gruplar olarak bildirilmiştir. Olgumuzda çakmak gazı soluma alışkanlığının arkadaşları tarafından bilindiği halde çocuğun ailesinin bu durumdan haberdar olmadığı bilgisine ulaşılmıştır.

Birçok ergen; merak, can sıkıntısı, arkadaş yönlendirmesi gibi nedenlerle bu maddeyi kullanır. Uçucu madde alımı ile birkaç dakika içinde öfori, eksitasyon ve neşeli davranışlar sergilenir. Sonra ise; konfüzyon, görsel halüsinasyonlar, en sonunda da hareketlerde yavaşlama görülür $(7,21)$. Literatürlerde uçucu madde kullanmaya başlayan ergenler için madde kullanımının artık arkadaşları ile yaptığı bir aktivite halini aldığını ve genelde toplumdan uzak parklar, köprü altları, terk edilmiş boş evler, inşaatlar, tren rayları gibi mekanlarda bu maddeyi kullandıkları bildirilmiştir (8). Olgumuzda da literatürle uyumlu olarak arkadaş grubu ile eğlenmek amacıyla ile boş bir evin çatısını gaz soluma amacıyla kullanılmıştır.

Butan gazı keyif verici özellikte olup oda spreylerinde ve deodorantlarda da bulunmakla birlikte ucuz ve kolay ulaşılabilir olması nedeniyle özellikle 15-20 yaş arası gençlerde kullanım yolu olarak çakmak gazı yoluyla soluma tercih edilmektedir $(22,23)$. Olgumuzda literatürle uyumlu olarak, ucuz, kolay elde edilebilir olması ve bulundurulması yasal yükümlülüik getirmemesi nedeniyle gaz soluma amacıyla

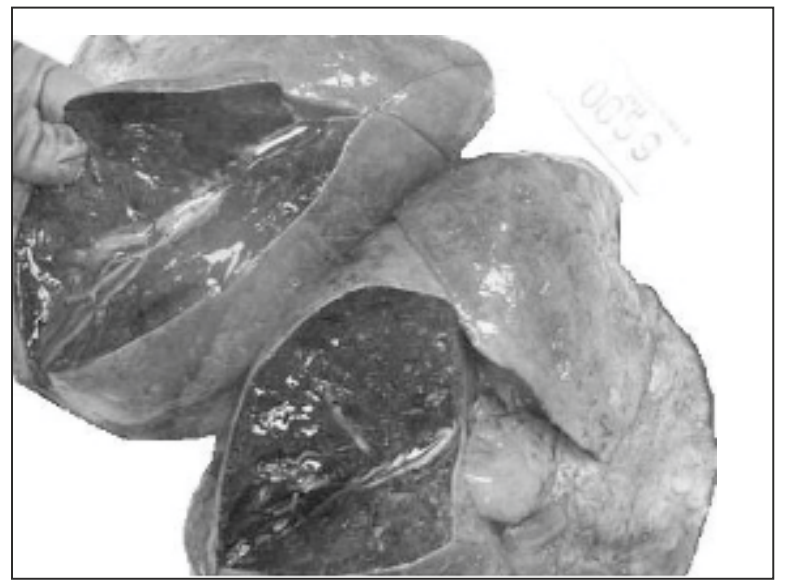

Resim 2. Akciğer kesitlerinde yoğun ödem.

çakmak gazı dolum tüpü tercih edilmiştir.

Uçucu madde inhalasyonunun Japonya'da gençler arasında yaygınlaştığı ve bu amaçla en sık olarak bütan içeren çakmak dolum tüplerinin kullanıldığı belirtilmektedir. Daha az sıklıkla piknik tüplerinde kullanılan ve yine bütan gazı içeren kutuların, nadiren de propan içeren ve genelde öldürücü olmayan sıvılaştırılmış petrol gazının (LPG) kullanıldığ belirtilmektedir (6). Akcan ve arkadaşları tarafından sunulan bir olgu raporunda, on dokuz yaşında kadın olgunun, arkadaşları ile birlikte çakmak gazı tüpünden gaz soluduktan sonra aniden fenalaştığı ve hastaneye kaldırılırken yolda öldüğü belirtilmektedir. Bu olguda, histopatolojik incelemede akciğer parankim kanaması ve iskemik kalp bulguları izlendiği, toksikolojik analizlerde herhangi bir madde saptanmadı̆̆ belirtilmektedir (24). Williams ve Cole tarafindan sunulan bir olguda; arkadaşları tarafından çakmak dolum tüpünden bütan gazı solumaya ikna edilen 15 yaşında bir kızın, gazı doğrudan ağzına sıkarak kullandığı, iki saat sonra aniden bayılarak hastaneye kaldırılan olgunun ventriküler fibrilasyon nedeniyle uzun süre tedavi gördüğü, ancak kan-idrar örneklerinde herhangi bir toksikolojik ajan saptanamadığ (10). Tekelioğlu ve arkadaşları tarafından sunulan çalışmada; yaklaşık 4 yıldır tutkal kullandığını belirtilen 19 yaşında erkek olgunun yanında çakmak gazı tüpüyle odasında kendinden geçmiş halde bulunduğu, hastaneye kaldırılan olgunun 27 gün tedavi sonrasında öldüğü ve kişinin ölümünün multiorgan yetmezliği, hipoksi ve akut koroner sendrom olduğu bildirilmiştir (25). Olgumuza ise, her ne kadar tıbbi müdahale görmüş olsa da, ani ölüm nedeni ile acil müdahaleler dışında incelenme olanağ 1 olmadı̆̆ından herhangi tan 1 konulamamıştır. Ölüm nedeni otopsisi sonrasında belirlenebilen olgumuzun kanında ise bütan tespit edilmiştir.

Rossi ve arkadaşlarının çalışmasında, cezaevindeki 
hücrelerinin içinde bilinçsiz halde bulunan biri 25, diğeri 50 yaşlarındaki iki erkek olgunun da başlarının naylon çanta ile sarılı olduğu ve bütan içerikli çakmak tüplerini bu naylon çantalara sıkarak kullandıkları belirtilmektedir. Toksikolojik incelemede kan, safra, mide, beyin, akciğer ve karaciğerde bütan rastlandığ nedeni asifiksiye bağlanmış olup yaygın iç organ konjensyonu, akciğer ve beyin ödemi olduğu bildirilmiştir (26). Olgumuzda da makroskopik ve mikroskopik asfiksi bulguları belirgin olup otopsisinden elde edilen verilerle ölüm nedeni n-bütan (çakmak gazı) intoksikasyonu olarak raporlanmıştır.

Uçucu madde soluma nedeniyle gelişen ani ölüm olgularında otopsinin olabilecek en erken dönemde yapılması gerekir (24). Olgumuzun ölüm saati ile otopsi saati arasında geçen süre kısa olmamakla birlikte 24 saatten daha azdı.

Sonuç olarak ülkemizde giderek artan bir halk sağlığı sorunu olan uçucu madde kötüye kullanımı konusuna yeterli ilginin gösterilmediği kanaatindeyiz. Uçucu maddeyi yasal ve kolay elde etme imkanı ergenlerin uçucu madde kullanımı yaygınlığında önemli bir faktördür. Ayrıca uçucu madde kullanımı diğer uyuşturucu maddeleri kullanmaya başlamada bir basamak oluşturmaktadır. Bu maddelerin satılması ve bulundurulması ile ilgili ilave düzenlemeler yapılması gerekmektedir. Ailelere, riskli gruplara ve eğiticilere yönelik eğitsel aktiviteler ile toplumun ve bireylerin kötüye kullanımın olası sonuçları konusunda bilgilendirilmeleri, özellikle çocuk ve ergenlere yönelik çalışan profesyonellerin bu konuda aktif rol alması gerektiğini düşünmekteyiz.

\section{Teşekkür}

$\mathrm{Bu}$ çalışmanın yapılmasında gerekli bilgilerin kullanılmasına imkan veren Adli Tıp Kurumu Başkanlığına teşekkür ederiz.

\section{Kaynaklar}

1. Crowley TJ İnhalant-Related Disorders. In: Kaplan \& Sadock's Comprehensive Textbook of Psychiatry, seventh edition, volume 1. Williams and Wilkins, Philadelphia, USA, 2000:1025-1033.

2. Spiller HA, Krenzelok EP. Epidemiology of inhalant abuse reported to two regional poison centers. Clinical Toxicology 1997; 35:167-173

3. Carlini-Cotrim B. Carlini EA The use of solvents and other drugs among children and adolescents from a low socioeconomic background: a study in San Paulo, Brazil. Int J Addict 1988; 23:11451156.

4. Alvarez FJ, Queipo D, Del Rio MC. Patterns of drug use by young people in the rural community of Spain. Brit J Addict 1989; 84:647652.

5. Kılıç E, Aysev A, Altınoğlu İ, Kerimoğlu E. Gençlerde uçucu madde bağımlılı̆̆ının nedenleri. 8. Ulusal Çocuk ve Ergen Psikiyatrisi Kongresi Bildiri Sunumları Tam Metin Kitab1, 2000:128-134.
6. Yaşan A, Gürgen F. Güneydoğu Anadolu Bölgesinde ergenlerde uçucu madde kullanım özellikleri. Bağımlılık Dergisi 2004;5:28-34.

7. Anderson CE, Loomis GA. Recognition and prevention of inhalant abuse. Am Fam Physician 2003; 68: 869-74.

8. Aklaş L, Sırma G, Ersül Ç. Umatemde yatarak tedavi gören çocuk ve ergenlerin özelikleri. VIII. Ulusal Çocuk ve Ergen Psikiyatrisi Kongresi Bilimsel Calıșmalar Kitabı, 2000: 38-42.

9. Altındağ A, Özkan M, Oto R. İnhalanla ilişkili bozukluklar. Klinik Psikofarmakoloji Bülteni 2001;11:143-8.

10. Williams DR, Cole SJ. Ventricular fibrillation following butane gas inhalation. Resuscitation 1998; 37:43-5.

11. Pfeiffer H, Al Khaddam M, Brinkmann B, Köhler H, Beike J. Sudden death after isobutene sniffing: A report of two forensic cases. Int J Legal Med 2006; 120:168-73.

12. Sugie $H$, Sasaki $C$, Hashimoto $C$ et al. Three cases of sudden death due to butane or propane gas inhalation: analysis of tissues for gas components. Forensic Sci Int 2004;143:211-4.

13. Sharp CW, Rosenberg N. Inhalant-related disorders, in. Tosman A, Kay J, Liberman AJ (editors). Psychiatry 1.st edition. Philadelphia: WB saunders company, 1997: 835-52.

14. Anderson CE, Loomis GA. Recognition and prevention of inhalant abuse. Am Fam Physician 2003; 68: 869-874.

15. Evren C, Öğel K, Tamar D, Çakmak D. Uçucu madde kullanıcılarının özellikleri. Bağımlılık Dergisi 2001; 2: 57-60.

16. Frederich M, Mackusy-Amiti ME, Muskan JS, Goldstein PJ. Childhood abuse and the use of inhalants: differences by degree of use. Am J Public Health 1997; 87: 765-69.

17. Aytaçlar S, Ertekin G, Türkcan A, ve ark. UMATEM'de yatan hastaların sosyodemografik özelikleri ve yaşam alanlarındaki sorunlarını değerlendirilme. XXXIII. Ulusal Psikiyatri Kongresi Bilimsel Çalışmalar Kitabı, 1997: 125.

18. Corlini-Cotrim B, Corlini EA. The use of solvents and other drugs among children and adolescents from a low socioeconomic background: a study in San Paulo Brazil. Int J Addict 1989; 84: 647652.

19. Carolini-Catrim B. Inhalant use among Brazilian youths. NIDA Res Monogr 1995;148: 64-78.

20. Westermayer J. The psychiatrist and solvent inhalant abuse: recognition assessment and treatment. Am J Psychiatry 1987; 903907.

21. Tapia Canyar R, Craviate P, De La Rosa B, Valaz C. Risk factors for inhalant abuse in juvenile offenders: the case Mexico. Addiction 1995; 90:43-49.

22. Ago M, Ago K, Ogata M. A fatal case of n-butane poisoning after inhaling antiperspiration aerosol deodorant. Leg Med (Tokyo) 2002; 4: 113-8.

23. Taylor JC, Norman CL, Bland JM. Trends in deaths associated with abuse of volatile substances 1971-1997. London; Department of Public Health, St. George Hospital Medical School. 1999.

24. Akcan R, Çekin N, Hilal A, Arslan MM. Gençlerde uçucu madde soluma sonucu ani ölüm: Olgu sunumu. Dicle Tıp Dergisi 2010;(37)2:154-56.

25. Tekelioglu U, Ocak T, Demirhan A, Erdem A, Tekelioglu V, Kocoglu H. Sudden death due to voluntary lighter fluid inhalation: A case report. International Journal of Medical Science and Public Health 2013;(2) 4:1128-30.

26. Rossi R, Suadoni F, Pieroni L, De-Giorgio F and Lancia M. Two cases of acute propanebutane poisoning in prison. J Forensic Sci 2012;(57)3:832-34. 